\title{
A Study on the Relationship Between Reflective-impulsive Cognitive Styles and Oral Proficiency of EFL Learners
}

\author{
Can Chen \\ Chongqing Normal University, China
}

\begin{abstract}
With the focus of language teaching from teachers to students, the personal factors of language learners have become the focus of research. In 1964, Kagan and his colleagues proposed a reflective-impulsive cognitive style(R-I), a pair of opposing cognitive style that can be measured by Matching Familiar Figures Test (MFFT). Kagan believes that in dealing with cognitive tasks, holding a slow but accurate style is a reflective cognitive style, and holding a fast but inaccurate style is impulsive cognitive style. What's more, different cognitive styles of learners affect language learning. For English learners, oral English is connected with the output of language, and students' oral ability is an important part of pragmatic competence. The researcher uses MFFT20, combined with observation, interview, oral test to evaluate the oral performance and ability of 80 high school students in a middle school in Chongqing. By analyzing the correlation between the reflective-impulsive cognitive styles and oral English ability, the following results are obtained. First, reflective cognitive style and impulsive cognitive style account for the same proportion of students. And reflective-impulsive cognitive style affects the oral ability of English learners. Second, students with different cognitive styles have great differences in oral performance. Third, generally speaking, English learners with reflective cognitive style perform better in oral accuracy than English students with impulsive cognitive style, while English learners with impulsive cognitive style perform better in oral fluency than students with reflective style.
\end{abstract}

Index Terms-reflective-impulsive cognitive style, oral ability, accuracy, fluency

\section{INTRODUCTION}

\section{A. Purpose of the Study}

Learners with different cognitive styles often have different interests, personalities, emotions, motivations, so they adopt different learning strategies to study. People, in the process of analyzing information, often choose the way that they think the most suitable for them to deal with information. This study is to explore the relationships between the oral performance and reflective-impulsive cognitive style of English learners. Not only to explore the characteristics of reflective-impulsive cognitive style of English learners in oral performance, but also to explore the different cognitive styles of different learners. And then teachers adopt corresponding teaching strategies, through teaching students in accordance with their aptitude, to improve student's oral English and overcome the shortcomings of student's oral English.

\section{B. Significance of the Study}

By recognizing the different cognitive styles of different English learners, it's known that student's performance in English learning will also be different. According to their differences based on their aptitude, teachers will as far as possible improve their oral ability. In addition, this study can also help teachers realize the advantages and disadvantages of reflective-impulsive cognitive style learners in oral English, not only to the students themselves. It also helps students learn from each other. Of course, because there is little research on reflective-impulsive cognitive styles, this study has enriched related research about it.

\section{Organization}

This study consists of five parts, the first part is about the general introduction, the purpose and the significance of this paper. The second part is a literature review on cognitive style, reflective-impulsive cognitive style, oral ability and the theoretical basis which includes the theory of constructivism and input and output theory. The third part introduces the experimental design and methods. The fourth part is about the teaching cases and the result analysis. The last part is about the conclusion, some limitations and future suggestions.

\section{LITERATURE REVIEW}

\section{A. Studies on Cognitive Styles}

Cognitive style is a psychological concept. The term was first put forward by Allport in 1937, and after that more and 
more different kinds of cognitive styles were researched and those styles became more and more important in the field of education. Messick (1984) divided the styles into 19 kinds. Riding (1991) divided it into more than 30 kinds. Style is the description of individual differences, referring to the individual in cognition, personality and other aspects of consistent external expression (Yang Zhilian, Guo Liping, 2001). Hu Binwu (1996) believes that cognitive style is a kind of learning style and learning tendency with distinct personality that learners show in long-term learning activities. This learning style refers to the methods, strategies, steps adopted by learners to complete their learning tasks. This learning tendency refers to learners' preference for motivation, attitude, emotion, experience, persistence and learning environment, learning content. Cheng Xiaotang (2002) believes that it refers to the way learners identify, process, store, extract information in the cognitive process and the starting point when learners solve problems, and sometimes become learning styles. Cognitive style is closely related to second language acquisition. And it can be divided into different types, with its own characteristics. Then according to different types of learners, teachers will also teach students according to their learning characteristics and cognitive styles.

\section{B. Reflective-impulsive Cognitive Styles}

\section{Definition and characteristics}

Reflective-impulsive cognitive style, also known as conceptual tempo, was proposed by kagan et al. in 1964. It refers to differences in the aspect of speed which individuals make decisions under uncertain conditions. And it generally can be divided into two different types, one is to make a quick decision after a brief examination of various possibilities, and the general error rate is relatively high, which is known as impulsive type. The other type is to think in detail before reaction, taking a certain amount of time to carefully consider all the possibilities, and the accuracy is relatively high, known as the reflective type (Huang Shilan, 2010). H. Douglas Brown (2007) also says that psychological studies have been conducted to make either a quick or gambling (impulsive) guess at an answer to a problem or a slower, more calculated (reflective) decision. In the process of foreign language learning, impulsive students may take quick steps, while reflective students may stay a little longer at some stages, but the step from one stage to another is larger.

2. Studies on reflective-impulsive cognitive styles

There is little research on reflective-impulsive cognitive style in the field of education. Li Zhe (2000) thinks that learners' cognitive style is closely related to their ability to solve problems. Impulsive cognitive style students answer questions quickly, while students with reflective cognitive style should analyze the details carefully and choose a sure answer after evaluating. But actually there is no difference in the nature of ability. Wang Lifei (1998) thinks that cognitive style has important enlightenment to foreign language teaching. Reflective and impulsive are two personality tendencies of human beings and a pair of learning styles in the category of cognition. The two cognitive styles have their own advantages. Reflective cognitive style promotes language accuracy, while impulsive style facilitates fluency. In contrast, students with impulsive cognitive style speak enthusiastically and dare to express their views and opinions in class. In addition, impulsive students show the characteristics of learning in a small increase, and it often ups and downs. While, to reflective one, learning stages are increased by a large amount and the stable period is longer.

\section{Studies on Oral Proficiency}

Based on the database, most of the researches on oral English ability are related to oral accuracy and fluency. When analyzing the evaluation criteria of oral ability, Wang Haihua and Yang Zai (2019) took the accuracy and fluency of spoken language as the standard, defined the accuracy as the degree of conformity of the second language output, and defined the fluency as the ability to speak continuously at a normal speed.

\section{Theoretical Foundation}

\section{Constructive Theory}

According to constructive theory, students should play a main role in the process of oral communication, actively explore and discover the meaning of constructing knowledge, connect the content of oral expression with their own experience and social reality. Meanwhile, students should think carefully, and improve their ability of analyzing and answering questions. Paying attention to students' cognitive styles equals paying attention to students' main position in class, which can focus on individual efforts, and encourage students to learn independently in various ways. The vivid eye for students' cognitive styles not only affirms the status of teachers, attaching importance to the role of teachers' guidance and promotion, but also fully embodies constructive learning theory and teaching theory. Constructivism emphasizes "cooperative learning ", and the oral practice advocates group cooperative activities and also attaches importance to the key role of "cooperative learning" in meaning construction.

2. Language Input-Output Hypothesis

Crashen (Krashen), a famous American linguist, holds that human language acquisition is not unconditional. In the process of human acquisition of language, the input of comprehensible language is primary. Besides, the difficulty of knowledge is slightly higher than that of learners themselves, but it can not be too high, that is the "i+1" principle". In the input stage before starting oral English teaching, Hammer advocates that the learning motivation and interest of students should be stimulated. And he emphasizes the importance of real context. In the process of oral teaching, teachers selectively organize students to carry out some interesting activities that accord with the students' existing level, and the topics of oral English reflect the situational authenticity. In oral teaching, both the stages of learning and 
application reflect the guidance of the language input hypothesis. Teachers and students communicate with each other in oral English, and at the same time, they achieve the purpose of using language. Those students can remember what they have learned and use language flexibly.

\section{Methodology}

\section{A. Questions}

This paper studies the relationships between reflective-impulsive cognitive style and the oral ability of English learners, and will answer the following questions:

1 , What are the reflective and impulsive cognitive styles and the differences between them?

2, Is reflective-impulsive Cognitive Style Related to Oral English Ability? What kind of relationships?

\section{B. Subjects}

This study selects 80 high school students in a middle school in Chongqing. First, the 80 students are tested in using match familiar figures tests in order to judge the cognitive style of the 80 students and then to observe and interview the students' performance in the oral English class, mainly the accuracy and fluency of oral English. This research combines with interviews about students and teachers will be analyzed. Finally, the 80 students are given an oral test to analyze the relationships between reflective-impulsive cognitive style and students' oral ability, and then the results provide further guidance for teachers' oral teaching.

\section{Instruments}

\section{MFFT20}

Matching familiar figure test is a special test of the reflective-impulsive cognitive style. MFFT20 is to let students identify 20 pictures, finding the most similar one. In the matching process, it can detect whether students are slow while accurate or fast but inaccurate to find the picture. And corresponding to this, the researcher can recognize who belong to the group with the reflective cognitive style or impulsive cognitive style.

\section{Observation}

According to the existing information - the cognitive styles of 80 students, it observes the performance of these students in oral English class. And it is necessary to make a record about students' performance. In oral English class, the accuracy and fluency of different styles of students are different, so it can explain the relationship between cognitive styles and students' oral ability.

3. Interview

The process of further perfecting and supplementing the experiment is by interviewing students and teachers. Researchers can interview students to understand their ideas about their own cognitive style and the judgment of their oral ability. Researchers can interview the teacher to see if the teacher understands the students and whether they are taught according to their cognitive style and learning characteristics.

4. Oral test

The oral test is to measure the students' oral English scores of different cognitive styles, to some extent, and it can also reflect the influence of cognitive style.

\section{RESULTS AND DISCUSSION}

\section{A. Performance in MFFT20 Test}

According to MFFT20 test, the researcher can know that 48 students belong to the group of reflective cognitive style, and 32 students belong to the group of impulsive cognitive style. It seems that there is not much difference in proportion between the two styles.

\section{B. Relationship between Reflective Cognitive Styles and Oral Proficiency}

Forty-eight reflective cognitive-style students raised their hands to answer questions 10 times in class. And those students who answered the questions slowly thought for a long time. But only 16 errors occurred at the knowledge level such as grammar.

\section{Relationship between Impulsive Cognitive Styles and Oral Proficiency}

The total number of hands raised by 32 impulsive cognitive style students in class is 36 , and the students who answered the questions could express their views fluently. But the number of errors about the knowledge such as grammar reached 50 .

\section{The Process of Interview}

For students, the following three questions are raised: 1, Do you think spoken English plays an important role in English? 2, Will you raise your hand to answer the questions in oral English class? 3, When you answer the question, you answer it directly or after careful thinking? According to the students' answers, combined with the MFFT20 test, the classification of students' cognitive styles can be identified accurately. And the students' interests in learning oral 
English and their learning situation also can be better analyzed.

For teachers, the following three questions are put forward: What do you think of the students' overall oral English performance? How many students answer questions positively in class? At present, what teaching methods do you adopt to teach oral English? By asking above questions, researchers know more about students' oral English level. Combined with teachers' answers, the research can also understand the relationship between teachers' teaching style and students' learning.

\section{E. Performance in Oral Test}

Next chart shows the student's scores of reflective-impulsive cognitive style in different grades.

\begin{tabular}{|l|l|l|}
\hline scores & Reflective CS & Impulsive CS \\
\hline$<60$ & 4 & 2 \\
\hline $60 \sim 70$ & 7 & 4 \\
\hline $70 \sim 80$ & 15 & 11 \\
\hline $80 \sim 90$ & 17 & 13 \\
\hline $90 \sim 100$ & 5 & 2 \\
\hline & 48 & 32 \\
\hline
\end{tabular}

From this chart, there are no apparent differences in the oral scores. And just as mentioned above, the cognitive styles influence the speed of answering questions and the grammar of the expressions. But generally speaking, the cognitive styles of students don't have the strong influence on oral scores.

\section{F. Teaching Cases}

\section{Case 1}

The teacher conducts a 40-minute oral English teaching class, and the topic of this class is "What is your dream?".

First of all, the researcher has a brief interview with the teacher after this class. The main content of this interview is the preparation part of the teacher before class and the reflection part after class (which can not be presented in the teaching video). Before class, the teacher spends a lot of time in preparing interesting topics which students want to attend. According to the needs of students, the theme of "dream" can not only attract students' interest, but also help students express their ideas freely. After setting the theme, the teacher predicts the students' oral performance and assumes some possible problems that may happen in the process of this class, based on the understanding of students. For example, the topic meets the interests of most students, but how to teach a small number of students who don't interested in this topic? The teacher's answer is to adopt to the principle of cooperation, and the positive students help those students with low interest to express themselves. The possible problem is that the topic is relatively simple, so students have less to express. And the class time of talking about "dream" is less than 40 minutes. In response to this problem, the teacher's answer is that another dream-related topic has been prepared. When people pursuit dreams, they will certainly encounter a lot of difficulties, only perseverance can help them to succeed. This is the teacher's preparation.

According to the teaching video record, teachers and students are generally very positive during this oral teaching class. A teacher attracts students' attention through a video and leads to topics---dreams. Before watching the video, the teacher asks the students a question, "Think about your dream when watching this video." After watching this video, the teacher first organizes the students to discuss about their dreams in groups. Then the teacher asks the students questions and the students answer the questions voluntarily. From the record, we can see that the degree of enthusiasm of students to answer questions is very high. Some students raise their hands quickly, and some students raise their hands relatively slowly, but most students answer questions. The students' answers are different, but they all have ideas. Under this topic discussion, another topic---the struggle and the persistence also is discussed. The teacher asks, "In the process of realizing your dream, when you encounter problems, what methods will you take to solve it?" Most students say they will persist and will not give up easily. The teacher affirms the student's answer and then mentions the benefits of persistence. "Persistence can not only bring success, but also be a good quality of a person and be a person's spiritual wealth." After class, the researcher learns from the students and the students can benefit a lot from this class.

Finally, the teacher will reflect the problems after class, as well as the parts that need to be improved. Combined with the preparation of the lesson, the experience will be summed up by the teacher. "Students are actively involved in class, and oral expression is fluent and accurate," the teacher said. "Overall, the performance of students is good. But there are also some problems, such as unreasonable class schedule, a small number of students participation is not high. These are the things I need to improve in the future, and I will improve my teaching ability."

Case 2

This is an oral class about the cultural differences between China and the United States. The goal of this class is that students can express their ideas and views on the cultural differences between China and the United States in complete sentences.

In the process of teaching, the teacher first guides students to express the food culture of China and the United States separately, and then has logically classified the information points which are put forward by students. Meanwhile the teacher guides students to compare those information between the two counties. The teacher will make a demonstration 
before the student expresses, then the students can speak freely. Before this class, the teacher clearly knows that students are familiar with Chinese food culture, while for American culture, students only know some simple and well-known food culture. Class begins, the teacher first puts forward a question to the students, that is, "what Chinese food culture do you know?" The students answer positively, and there are following answers: we use chopsticks to eat; when we eat, the elders sit in the position which stands for status; when we eat, we can't talk; Don't eat until your elders say you can, etc. Then the teacher asks another question, "What American culture do you know?" Students have the following answers: people eat with forks and knives, with forks in their left hand and knives in their right hand; everyone eats with a pot alone; when eating, people can speak and discuss. The teacher affirms the students' answers and adds other points based on their answers. The teacher mentions that the differences between Chinese and American cultures are made up of many reasons. First of all, the historical origin. China is an ancient country with 5000 years of cultural heritage. Traditional Confucian culture has a profound influence on food culture. The United States is a young federal republic with a history of more than 200 years. It is multi-ethnic, multicultural, democratic, free, independent and equal. Secondly, there are great differences in social atmosphere. China emphasizes the collectivism and the hierarchy, and the United States emphasizes the individualism and equality. Finally, economic development. Since the reform and opening up, with the development of economy and the deepening of cultural exchanges between China and the West, China's diet is getting better and better, and the variety of dishes also represents a relatively rich standard of living. But the United States is a developed country, the education level is high. So Americans are easily satisfied, and do not pursue too many dishes." In this class, the students are actively involved in the discussion. Because students have different cognitive styles, their performance is also different. The students with reflective cognitive styles think longer than the students with impulsive cognitive style. At the same time, students who think in a long time make fewer mistakes than students who think in a short time. At the end of the class, the teacher gives the feedback, "The effect of this class is very good, because the topic is close to real life. Students actively express their views."

The two teaching cases show the differences between the students of two different cognitive styles in the aspect of answering questions. And the teachers also make improvement measures according to the characteristics of students with different cognitive styles. For example, the cooperative principle teaching method is adopted to let students discuss with each other, so as to achieve better teaching effects.

\section{CONCLUSION}

\section{A. Major Finding}

First of all, 80 students are judged as reflective-type cognitive style or impulsive cognitive style by MFFT20. The student number of reflective cognitive style is 48 , and impulsive cognitive style is 32 . But both styles have its advantages and disadvantages, without judging it good or bad.

Secondly, cognitive style will have an impact on student's oral English, and reflective-impulsive cognitive style is related to students' oral English ability.

Finally, students with reflective cognitive styles think about questions for a long time, so the fluency of student's English is not high but the accuracy of answering questions is high. Students with impulsive cognitive style can quickly and fluently answer questions and express ideas, but the error rate is high, that is, low accuracy.

\section{B. Implication}

Reflective-impulsive cognitive style is closely related to students' oral ability, so both teachers and students should make good use of learning characteristics in order to achieve the best teaching effect and learning effect. For teachers, they should understand the cognitive styles of students, and then make teaching design according to the styles of students. For students, understanding their own cognitive style can achieve twice the result with half the effort.

\section{Limitation}

There is still insufficient theoretical guidance for this study, especially foreign literature. In addition, the research content is not rich enough, only talking about the enlightenment to the teaching and no deep excavation. Finally, the practical significance of the research is not enough.

\section{Suggestions for Further Research}

The relationships between reflective-impulsive cognitive styles and other aspects of English ability can be studied in order to carry out teaching design concretely and pertinently. Visiting more domestic and foreign literature helps laying a good foundation for study. Enriching the research content and using more perfect research approaches make the research process more detailed and clear.

\section{REFERENCES}

[1] Cheng Xiaotang. (2002). English learning strategy. Beijing: Foreign Language Teaching and Research Press, 13-15.

[2] Hu Binwu. (1996). The choice of learning style and learning strategy. Shanghai: Shanghai Education and Research Institute (9):38-39.

[3] H. Douglas Brown. (2007). Principle of language learning and teaching, Fifth Edition. New York: Person Education, Inc. 
[4] Huang Shilan. (2010). The impact of reflective-Impulsive cognitive style on language learning. Hunan: Literati (09):262-262.

[5] Li Zhe. (2000). The difference of learners' cognitive styles and foreign language teaching. Shanxi: Foreign Language Teaching (03):61-64

[6] Messick,S. (1984). The psychology of education measurement. Journal of Educational Measurement 21 (3):215-237.

[7] Riding, R., J., \& Cheema, I. (1991). Cognitive styles: An overview and Integration. Educational Psychology, 11, $193-215$.

[8] Wang Haihua, \&Yang Zai. (2019). The analysis of evaluation criteria of oral English ability. Shanxi: Journal of Jincheng Vocational and Technical College (6):59-62.

[9] Wang Lifei. (1998). Cognitive style research and implications for foreign language teaching. Shandong: Shandong Foreign Language Teaching (4):65-69.

[10] Yang Zhilian, \&Guo Liping. (2001). The research progress of cognitive style. Psychological Science (3):326-329.

Can Chen was born in Chongqing, China in 1996. She received her bachelor degree in English from Xinjiang University, China in 2019.

She is currently a graduate student in the School of Foreign Languages, Chongqing Normal University, Chongqing, China. She is major in English education.

Ms. Chen won the second prize in National English Contest for College Students (NECCS) in 2017 and 2018 respectively. 